\title{
NEW GENE MARKERS INVOLVED IN REGULATION OF GRANULOSA CELLS DEVELOPMENT AND DIFFERENTIATION TOWARDS ENDODERMAL AND EPITHELIAL TISSUES - A NEW INSIGHT INTO THE STEMNESS SPECIFICITY OF OVARIAN FOLLICULAR CELLS
}

Wiesława Kranc ${ }^{1}$, Małgorzata Popis ${ }^{1}$, Claudia Dompe ${ }^{1}$, Afsaneh Golkar-Narenji ${ }^{2}$, Michal Jeseta ${ }^{3,4}$, Paul E Mozdziak $^{2,5}$, Elena Kistanova ${ }^{6}$, Alexander Makarevich ${ }^{7}$, Marie Machatkova $^{8}$, Dorota Bukowska ${ }^{9}$, Radek Prochazka ${ }^{10}$, Jędrzej M. Jaśkowski ${ }^{9}$, Kornel Ratajczak ${ }^{11}$, Jarosław Sobolewski ${ }^{12}$, Paweł Antosik ${ }^{11}$

\begin{abstract}
Maintaining of female fertility is strictly dependent on proper hormonal regulation. Granulosa cells (GCs) are components of ovarian follicles, and they are important in paracrine regulation of the ovary. Preovulatory follicle GCs are responsible for production of estrogens to the ovary microenvironment and lead to the LH surge. Proper functioning of GCs is necessary to ensure appropriate conditions for oocyte development, maturation, ovulation and its release to the oviduct. Long-term in vitro culture of GCs show significant stem-like characteristics. Understanding the molecular processes underlying GCs differentiation towards different cell lineages may reveal other possible stem cell markers. A transcriptomic analysis of short-term primary in vitro cultured GCs, which were isolated from porcine preovulatory follicles was the major focus of the study. The ontological groups herby considered are associated with endodermal and epithelial tissues. Results were and compare to freshly isolated GC cells. 6 the most reduced expression: HSD17B1, DAPL1, NEBL, MAL2, DAB1, ITM2A were chosen for analysis. These genes have been response for processes associated with GCs development and differentiation towards endodermal and epithelial tissues, which make them important for further consideration.
\end{abstract}

Running title: GCs - endodermal and epithelial tissues differentiation

Keywords: porcine granulosa cells, ovaries, cell culture

\footnotetext{
${ }^{1}$ Department of Anatomy, Poznań University of Medical Sciences, Poznań, Poland

${ }^{2}$ Prestage Department of Poultry Science, North Carolina State University, Raleigh, NC, USA

${ }^{3}$ Department of Obstetrics and Gynecology, University Hospital and Masaryk University, Brno, Czech Republic

${ }^{4}$ Department of Veterinary Sciences, Czech University of Life Sciences in Prague, Prague, Czech Republic

${ }^{5}$ Physiology Graduate Program, North Carolina State University, Raleigh, NC, USA

${ }^{6}$ Institute of Biology and Immunology of Reproduction, Bulgarian Academy of Sciences, Sofia, Bulgaria

${ }^{7}$ National Agricultural and Food Centre, Research Institute of Animal Production Nitra, Nitra, Slovak Republic

${ }^{8}$ Veterinary Research Institute, Brno, Czech Republic

${ }^{9}$ Department of Diagnostics and Clinical Sciences, Institute of Veterinary Medicine, Nicolaus Copernicus University in Toruń, Toruń, Poland

${ }^{10}$ Laboratory of Developmental Biology, Institute of Animal Physiology and Genetics of the Czech Academy of Sciences, Liběchov, Czech Republic

${ }^{11}$ Department of Veterinary Surgery, Institute of Veterinary Medicine, Nicolaus Copernicus University in Toruń, Toruń, Poland

${ }^{12}$ Department of Public Health Protection and Animal Welfare, Institute of Veterinary Medicine, Nicolaus Copernicus University in Toruń, Toruń

*Correspondence: pantosik@umk.pl

Full list of author information is available at the end of article
} 


\section{Introduction}

The ovarian follicle consists of different types of cells, such as of oocytes (OCs), theca cells, ovarian surface epithelial cells and granulosa cells (GCs). GCs not only are fundamental for folliculogenesis and oogenesis, but they are also involved in cell communication. Releasing exosomes, small vesicles secreting miRNAs, and forming gap-junctions, they exchange nutrients and metabolites with OCs. The bidirectional stimulation allowed by gap-junctions promotes communication and reciprocal maturation stimulation between OCs and GCs, enhancing folliculogenesis and oogenesis [1].

Ovarian follicular cells show stem-like potential as they show changes in phenotype during longterm in vitro cultures and the ability to differentiate towards multiple cell lineages. For example, studies have demonstrated the ability of GCs under specific culture conditions, to express genes characteristic for heart morphogenesis but also osteogenic differentiation [2-4]. Understanding the process of differentiation of GCs towards different cell lineages and the molecular pathways underlying this mechanism is fundamental to uncover other possible stem cell markers of GCs [5].

The follicular epithelium is much more dynamic than the epithelium in the rest of the body. The follicular epithelium expands as the follicle grows. The number of layers of granulosa, forming the follicular epithelium, grow around the oocyte. Subsequently, the follicular epithelium expands laterally. However, the understanding of the follicular epithelial dynamics, which may disrupt if the follicle becomes atretic, remains poorly understood [6].

The endoderm is one of the three main germ layers and, after gastrulation, it primarily gives rise to the respiratory and digestive tracts together with being part of many glands, including thyroid, thymus, pancreas, and liver [7]. It is hypothesized that in vitro endoderm stem cells may give rise to a multitude of tissues. However, this type of stem cell is not yet fully characterized. Moreover, during embryonic development the endoderm forms the extraembryonic endoderm of the yolk sac where primordial germ cells are found. In vertebrates, these cells migrate to the gonad rudiments and arise outside the gonads.

The present study reports the transcriptomic profile of porcine GCs during their short-primary culture during $168 \mathrm{~h}$. The main goal of presented study has been identify genes group response for processes associated with epithelium and endoderm development.

\section{Material and Methods \\ Animals and tissue collection}

The material for research were isolated post-mortem from 40 mature gilts, which whose median age was 170 days and body weight $98 \mathrm{~kg}$. After cutting the abdominal wall in the linea alba, the reproductive system was removed along with the dige- stive tract. The ovaries were severed together with a large fragment of broad ligament of uterus and transported to the laboratory at $38^{\circ} \mathrm{C}$ in $0.9 \% \mathrm{NaCl}$ within $30 \mathrm{~min}$. In the laboratory, each ovary was removed from the ovarian bursa which was deep and voluminous.. The ovaries were ovoid in shape with a median length of $4,4 \mathrm{~cm}$. Outer surface was coarse lumpy as mulberry fruit. The appearance of the outer surface of the ovaries was determined by ovarian follicles located in the parenchymatous zone.

\section{Granulosa cells isolation and primary short-term cultivation}

Ovaries $(\mathrm{n}=80)$ after isolation, were incubated 15 min. in $38^{\circ} \mathrm{C}$ in $0.9 \% \mathrm{NaCl}$. Thereafter, follicular fluid (FF) has been obtained from single preovulatory large follicles (diameter estimated greater than 5 $\mathrm{mm}(\mathrm{n}=320))$. All follicle have been punctured using sterile 20 -G needle and syringe. Cumulus-oocyte complexes (COCs) were recovered and discarded. The follicular fluid with granulosa cells were used in research next step. FF with granulosa cells were centrifuge in $250 \mathrm{rpm}$ (10 min, RT). After supernatant discarded, pellet were incubated $10 \mathrm{~min}$. with collagenase type II $(1 \mathrm{mg} / \mathrm{ml})$ (Invitrogen, USA). Cells pellet after centrifugation (RT, $250 \times \mathrm{g}, 10 \mathrm{~min}$.) has been suspend in culture medium. Culture medium consisted of Dulbecco's Modified Eagle's Medium (DMEM, Sigma-Aldrich, USA), 10\% fetal bovine serum (FBS) (Sigma-Aldrich, USA), $200 \mathrm{mM}$ L-glutamine (Invitrogen, USA), $10 \mathrm{mg} / \mathrm{ml}$ gentamycin (Invitrogen, USA), 10,000 units $/ \mathrm{ml}$ penicillin and $10,000 \mu \mathrm{g} / \mathrm{ml}$ streptomycin (Invitrogen, USA). Cells were cultivated at $38.0^{\circ} \mathrm{C}$ under aerobic conditions $\left(5 \% \mathrm{CO}_{2}\right)$. When confluence were more than $90 \%$, cells were detached with $0.05 \%$ trypsin-EDTA (Invitrogen, USA) for 3-5 $\mathrm{min}$. After them, cells have been passaging.

\section{RNA isolation}

Cells in 4 time point of cell culture: $0 \mathrm{~h}, 48 \mathrm{~h} 96 \mathrm{~h}$, $144 \mathrm{~h}$ were detached from cultures using $1 \mathrm{x}$ Trypsin solution Sigma-Aldrich Co., St. Louis, MO, USA). After centrifugation cells pellet was resuspend in TRI Reagent (Sigma-Aldrich Co., St. Louis, MO, USA). Samples have been stored in $-80^{\circ} \mathrm{C}$.Total RNA have been isolated according Chomczyński-Sacchi protocol [8].

The total amount of RNA have been evaluated based on optical density at $260 \mathrm{~nm}$. Purity has been determined using 260/280 $\mathrm{nm}$ absorption ratio (NanoDrop 2000 spectrophotometer, Thermo-Fisher Scientific, Waltham, MA, USA). Only samples with RNA concentration over 500 ng and 260/280 absorption ratio higher than 1.8 were used in further studies (microarrays and RT-qPCR).

\section{Microarray expression analysis and statistics}

Briefly cDNA was subjected from Total RNA (100ng) (Ambion ${ }^{\circledR}$ WT Expression Kit). Obtained cDNA was biotin labeled and fragmentated by Affymetrix GeneChip ${ }^{\circledR}$ WT Terminal Labeling and Hy- 
bridization (Affymetrix). Biotin-labeled fragments of cDNA $(5.5 \mu \mathrm{g})$ were hybridized to Affymetrix $\AA$ Porcine Gene 1.1 ST Array Strip $\left(48^{\circ} \mathrm{C} / 20 \mathrm{~h}\right)$. Then, microarrays were washed and stained according to the technical protocol using Affymetrix GeneAtlas Fluidics Station. Subsequently the array strips were scanned by Imaging Station of GeneAtlas System. The preliminary analysis of the scanned chips was performed using Affymetrix GeneAtlasTM Operating Software. The quality of gene expression data was checked according to quality control criteria provided by the software. Obtained CEL files were imported into downstream data analysis software. All of presented analyses and graphs were performed by Bioconductor and R programming language. Each CEL file was merged with a description file. In order to correct background, normalize and summarize results, we used Robust Multiarray Averaging (RMA) algorithm.

Statistical significance of analyzed genes was performed by moderated t-statistics from the empirical Bayes method. Obtained p value was corrected for multiple comparisons using the Benjamini and Hochberg's false discovery rate. The selection of significantly changed gene expression was based on p-value beneath 0.05 and expression fold higher than 2 . Differentially expressed genes were subjected to the selection of genes involved in regulation of granulosa cells differentiation towards endodermal and epithelial tissues. Differentially expressed gene list were uploaded to DAVID software (Database for Annotation, Visualization and Integrated Discovery), where "developmental process", "cellular developmental process", "regulation of cell differentiation", "epithelium migration", “epithelial cell proliferation", "epithelial cell migration”, "epithelial cell differentiation", "epithelial cell development", "endodermal cell differentiation", "endoderm formation", "endoderm development" and "epithelium development" GO BP terms were obtained. Expression data of these genes were subjected to hierarchical clustering procedure and presented as a heatmap graph. Detailed analysis of genes belonging to selected GO BP terms were presented as plots using "GOplot" library [9].
Moreover, the interactions between proteins coded by selected genes and genes itself were investigated by STRING10 software (Search Tool for the Retrieval of Interacting Genes). STRING database contains information of protein/gene interactions, including experimental data, computational prediction methods and public text collections. STRING database engine provided us molecular interaction network formed between interested genes. Searching criteria based on co-occurrences of genes/proteins in scientific texts (textmining), coexpression and experimentally observed interactions.

Finally the functional interaction between genes that belongs to the chosen GO BP terms were investigated by REACTOME FIViz application to the Cytoscape 3.6.0 software. The Reactome FIViz app is designed to find pathways and network patterns related to cancer and other types of diseases. This app accesses the pathways stored in the Reactome database, allowing to do pathway enrichment analysis for a set of genes, visualize hit pathways using manually laid-out pathway diagrams directly in Cytoscape, and investigate functional relationships among genes in hit pathways. The app can also access the Reactome Functional Interaction (FI) network, a highly reliable, manually curated pathway-based protein functional interaction network covering over $60 \%$ of human proteins.

\section{Microarray results validation}

Six randomly selected downregulated genes belonging to selected ontological groups were validated (Tab. 1). Isolated RNA was reverse transcribed according to the Transcriptor First Strand cDNA Synthesis Kit (Roche Life Sciences, Basel, Switzerland) protocol and the Eppendorf Mastercycler $₫$ Nexus (Eppendorf AG, Hamburg, Germany). The RT-qPCR validation was then performed on a Lightcycler 96 (Roche Life Sciences, Basel, Switzerland). In reaction has been used Eva Green (Syngen Biotech, Wrocław, Poland) as a detection dye. The final reaction mix consisted: $1 \mu \mathrm{l}$ of cDNA, $0,5 \mu \mathrm{l}$ of forward primer, $0,5 \mu \mathrm{l}$ reverse primer, $2 \mu \mathrm{l}$ of Eva Green and $6 \mu \mathrm{l}$ of nuclease free water. The genes primers were designed based on Ensembl transcript se-

TABLE 1. The 6 most downregulated genes involved in regulation of granulosa cells differentiation towards endodermal and epithelial tissues were validated using RT-qPCR, 168h/0h

\begin{tabular}{|c|c|c|c|}
\hline GENE NAME & GENE SYMBOL & $\begin{array}{c}\text { FOLD CHANGE } \\
48 \mathrm{H} / 0 \mathrm{H}\end{array}$ & ADJ. P. VAL. \\
\hline integral membrane protein $2 \mathrm{~A}$ & ITM2A & -8.85 & $<0.05$ \\
\hline disabled homolog 1 (Drosophila) & DAB1 & -8.91 & $<0.05$ \\
\hline mal, T-cell differentiation protein 2 & MAL2 & -21.75 & $<0.05$ \\
\hline nebulette & NEBL & -26.72 & $<0.05$ \\
\hline death associated protein-like 1 & DAPL1 & -28.69 & $<0.05$ \\
\hline hydroxysteroid (17-beta) dehydrogenase 1 & HSD17B1 & -35.75 & $<0.05$ \\
\hline
\end{tabular}


TABLE 2 Primer sequences (5'-3')

\begin{tabular}{c|c|c}
\hline GENE NAME & GENE SYMBOL & PRIMER SEQUENCES (5'-3') \\
\hline integral membrane protein 2A & ITM2A & $\begin{array}{l}\text { TCTCGTAGGCCTTCCTTCA } \\
\text { AGGCAGGAAGTAGGGCTCTC }\end{array}$ \\
\hline disabled homolog 1 (Drosophila) & DAB1 & $\begin{array}{l}\text { TACGTTTGTGGGAAGGAAGG } \\
\text { CTTCCTTCTTTTGGCTGGTG }\end{array}$ \\
\hline mal, T-cell differentiation protein 2 & MAL2 & $\begin{array}{l}\text { AGGATGGGTCATGTTCGTGT } \\
\text { TTGTCATTCAAGAGCGGCTG }\end{array}$ \\
\hline nebulette & NEBL & $\begin{array}{l}\text { CAAACCCTTCAAGGCTACCA } \\
\text { CTGAGAACACGCTTCCATCA }\end{array}$ \\
\hline death associated protein-like 1 & DAPL1 & $\begin{array}{l}\text { CCTGCTCTGGAGAAGGTCAC } \\
\text { GGGCCTAAGGAAAGTTTGG }\end{array}$ \\
\hline
\end{tabular}

quences [10], using the Primer3 software (Tab. 2) [11]. The design process was based on the exon-exon method to avoid potential remnant genomic DNA amplification. Furthermore, the primers were designed to match all of the known protein-coding transcript variants. The results have been calculated based on the $2^{-\triangle \Delta C T}$ method, with 3 genes used as housekeeping genes: ACTB (beta-actin) and HPRT1 (hypoxanthine phosphoribosyltransferase 1) and GAPDH (glyceraldehyde 3-phosphate dehydrogenase) [12].

\section{Results}

The Affymetrix ${ }^{\circledR}$ Porcine Gene 1.1 ST Array Strip for the microarray gene expression was employed for the analysis of porcine granulosa cells. The array method allowed us to study the gene expression of 27,558 transcripts at $0,48,96$ and $144 \mathrm{~h}$ of in vitro porcine granulosa cell culture. We selected genes with more than 2 - fold changes and corrected p-values less than 0.05 for downstream analysis. A total of 3380 differentially expressed genes (DEGs) were identified according to the above criteria. Microarray gene expression analysis began by subjecting the list of DEGs to DAVID software, which showed that the genes can be assigned to 775 GO BP, 33 GO MF and 125 GO CC gene ontology terms. The focus of the study was on genes involved in regulation of granulosa cells differentiation towards endodermal and epithelial tissues. The DAVID software indicated the following GO BP terms, which cover the above processes: "developmental process", "cellular developmental process", "regulation of cell differentiation", "epithelium migration", "epithelial cell proliferation", "epithelial cell migration", "epithelial cell differentiation", "epithelial cell development", "endodermal cell differentiation", "endoderm formation", "endoderm development" and "epithelium development". The 360 genes involved in those processes were clustered using hierarchical clustering and presented as heatmaps (Fig. 1). 205 genes were upregulated while 155 genes were downregulated. The 6 genes, their symbols, fold changes and corrected p-values are shown in table 1.

z-scores analysis reveals whether molecular function is more likely to be decreased (negative value) or increased (positive value). The z-scores were presented as segments of inner circles in the figure 2. Expression of most genes was increased (red dots) in all ontological groups. The z-scores of the GO BP terms had positive values, indicating the processes described by these GO BP terms were upregulated. The expression pattern did not change at any of the analyzed time points. Considering the above, the subsequent analysis was based only on $48 \mathrm{~h} / 0 \mathrm{~h}$ comparison.

The interaction between selected ontological groups was examined and and are presented in as dendrogram (Fig. 3). Clusters contain functionally related genes based on their expression pattern. The middle circle represents a logarithm of fold change ( $\log \mathrm{FC})$ of differentially expressed genes assigned to the studied GO terms. The GO terms are shown as the outer ring. The genes whose expression is downregulated form clusters marked by blue part of the middle circle and analogously, red indicates upregulated genes. Clusters of the same color over the entire width of the outer circle represent genes that are unique for a specific GO term. Clusters of different colors on the cross section of outer circle show sets of genes which are likely to be functionally related. The dendrogram showed that many genes belong simultaneously to "cellular developmental process", "developmental process" and "regulation of cell differentiation". The genes that are unique for a specific GO term belong mainly to "developmental process".

In the gene ontology database, single genes may belong to many ontological terms. For this reason, we used plots with visualization of $\operatorname{logFC}$ values and relationship between genes and selected GO BP terms (Fig. 4). The relationship was also presented as a heatmap (Fig. 5). The strongest upregulated genes 

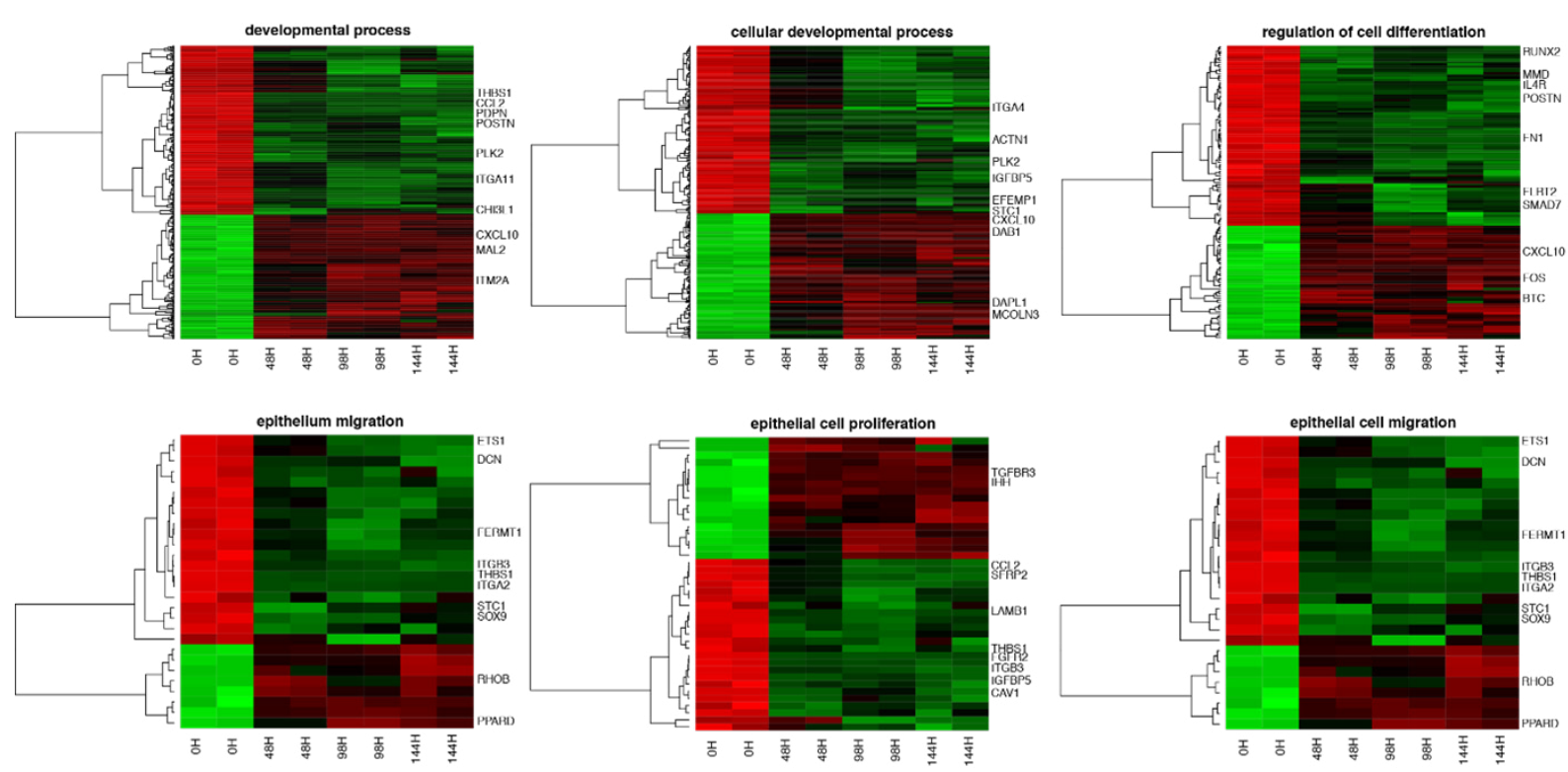

epithelial cell proliferation
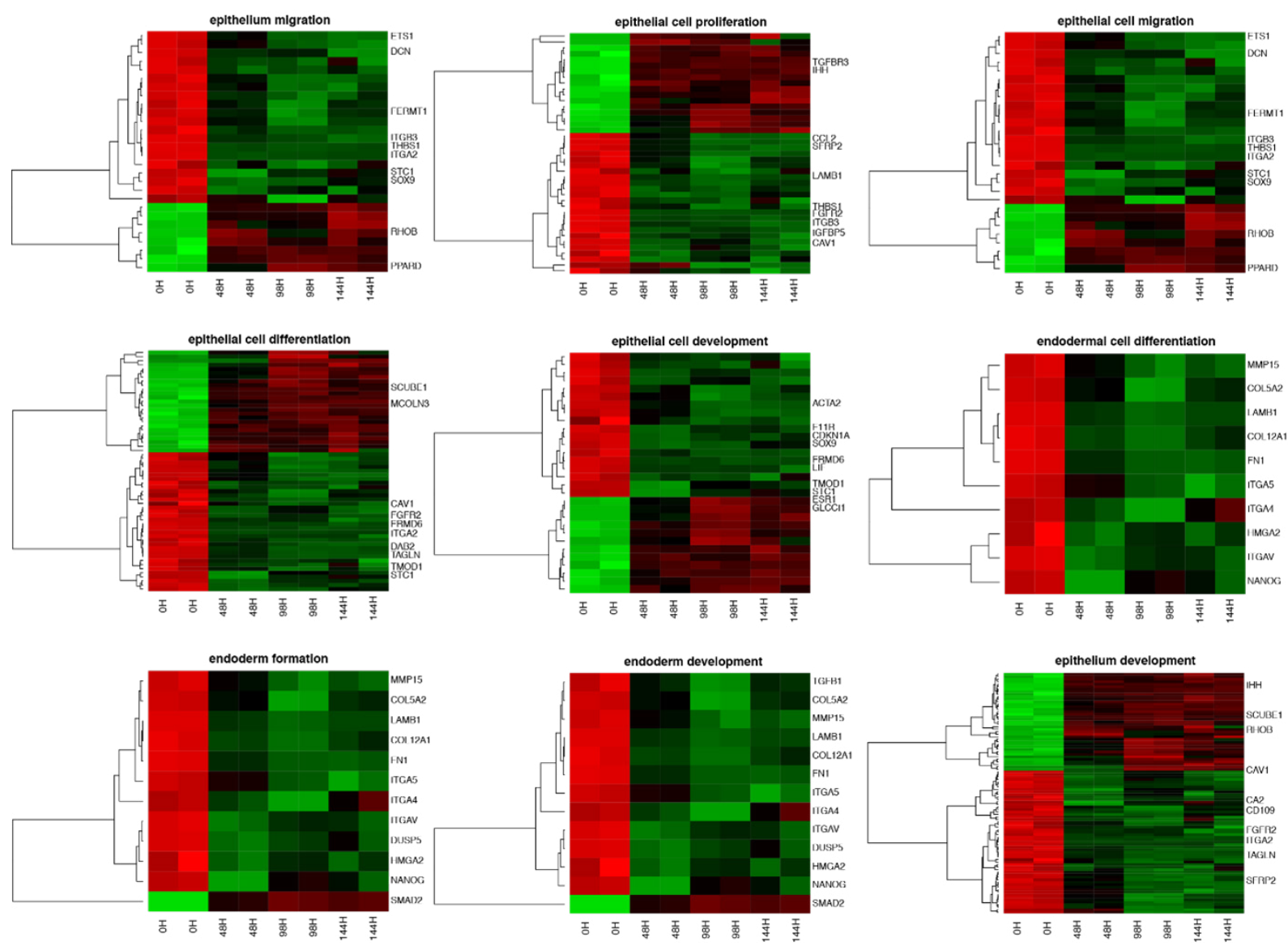

FIGURE 1 Heatmaps presenting differentially expressed genes involved in "developmental process", "cellular developmental process", "regulation of cell differentiation", "epithelium migration", "epithelial cell proliferation", "epithelial cell migration", "epithelial cell differentiation", "epithelial cell development", "endodermal cell differentiation", "endoderm formation", "endoderm development" and "epithelium development" based on GO BP terms. Each row on the Y axis represents a single transcript. The red color indicates downregulated genes while the green are upregulated

from examined GO BP terms included, among others: ITGA2- integrin, alpha 2; FN1- fibronectin 1; LAMB1laminin, beta 1; LOX- lysyl oxidase; POSTN- periostin, osteoblast specific factor. The most downregulated genes are: HSD17B1- hydroxysteroid (17-beta) dehydrogenase 1; DAPL1- death associated proteinlike 1; CXCL10- chemokine (C-X-C motif) ligand 10.

Finally, we used ReactomeFIViz app for investigation of functional interactions between proteins encoded by DEGs belonging to selected GO BP terms. Among the most significantly enriched functional interaction networks was FI networks for "positive regulation of cell proliferation" (Fig. 6).
Genes involved in the following processes: "developmental process", "cellular developmental process", "regulation of cell differentiation", "epithelium migration", "epithelial cell proliferation", "epithelial cell migration", "epithelial cell differentiation" ,"epithelial cell development" "endodermal cell differentiation" ,"endoderm formation", "endoderm development" and "epithelium development" were validated (Fig. 7). The main aim of the study was to validate the expression directions of the selected genes. In the case of 6 genes, the direction of expression was confirmed by the RT-qPCR method at individual intervals. 

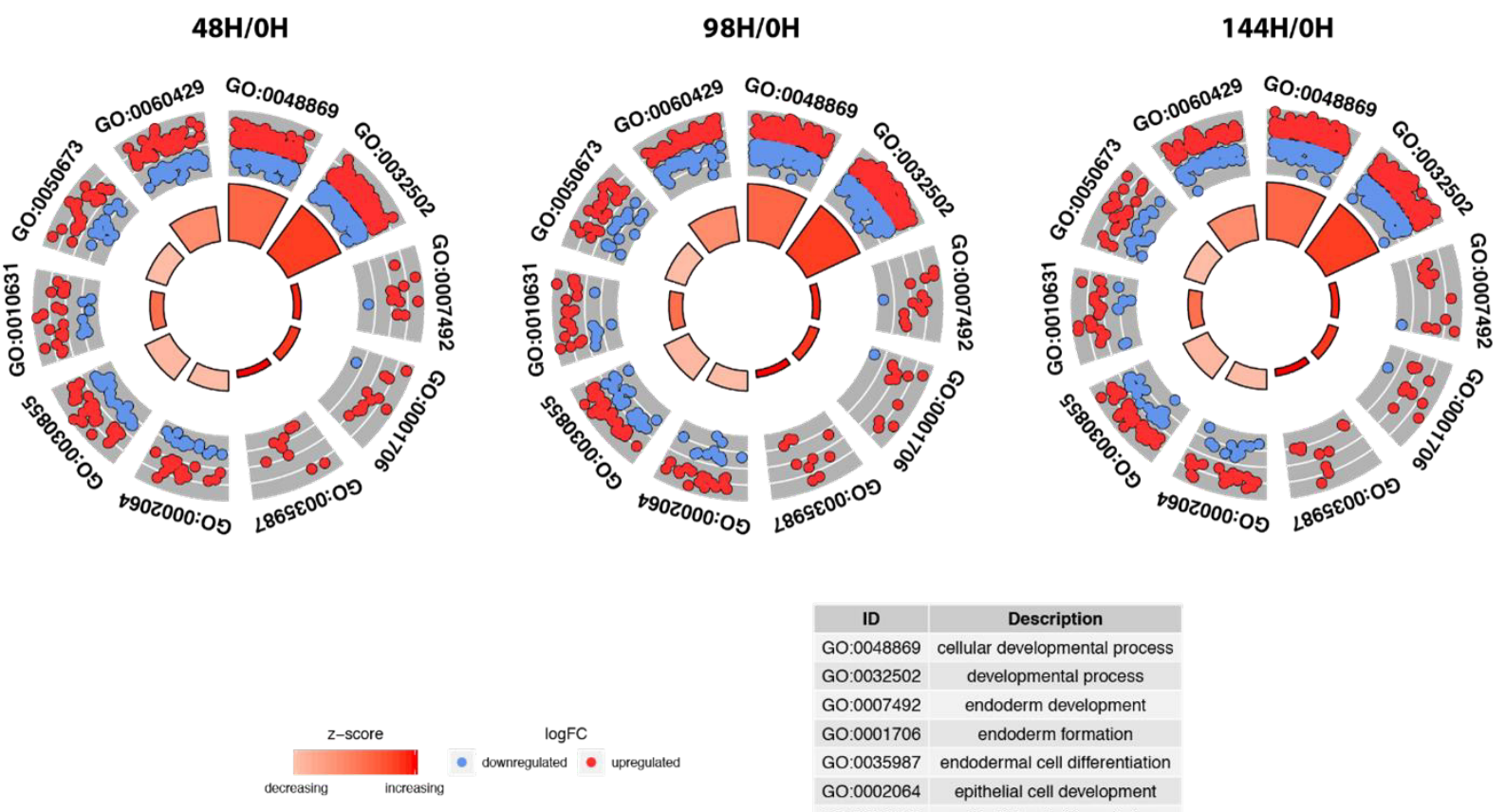

\begin{tabular}{|c|c|}
\hline ID & Description \\
\hline GO:0048869 & cellular developmental process \\
\hline GO:0032502 & developmental process \\
\hline GO:0007492 & endoderm development \\
\hline GO:0001706 & endoderm formation \\
\hline GO:0035987 & endodermal cell differentiation \\
\hline GO:0002064 & epithelial cell development \\
\hline GO:0030855 & epithelial cell differentiation \\
\hline GO:0010631 & epithelial cell migration \\
\hline GO:0050673 & epithelial cell proliferation \\
\hline GO:0060429 & epithelium development \\
\hline
\end{tabular}

FIGURE 2. The circular scatter plots of differentially expressed genes involved in "developmental process", "cellular developmental process", "regulation of cell differentiation", "epithelium migration”, "epithelial cell proliferation", "epithelial cell migration", "epithelial cell differentiation", "epithelial cell development", "endodermal cell differentiation", "endoderm formation", "endoderm development" and "epithelium development" GO BP terms. Each dot represents a single gene. The z-scores were presented as segments of inner circles

\section{Discussion}

Several recent studies have suggested that every tissue and organ contain a population of cells with stem-like properties, including the ovary [13-15]. Stem cells were found both in mouse and human ovaries, and they were observed to be involved in the processes of oogenesis and folliculogenesis. Specifically, granulosa cells (GCs) show programmed stem cell properties during in vitro culture $[16,17]$. These cells surround the oocytes and are fundamental for the functioning of the reproductive system and the maintenance of pregnancy releasing hormones. As these stem cells sustains the formation of the oocyte and the follicle in the postnatal mammalian ovary, the belief that females have a determined number of primordial follicles formed in the embryonic period was suggested to be wrong [18]. The great plasticity of GCs, showing stem cells properties, has been suggested as a therapeutic intervention for regenerative medicine and transplantology. Multiple studies present the ability of the GCs to go through transdifferentiation, by which already differentiated cells can be reprogrammed towards a different cell lineage [19].

Further understanding of the molecular basis underlying these processes and of the cells in the reproductive system may reveal the functioning of determined clinical diseases, potentially leading to therapies and treatments of diverse conditions, such as infertility. Microarray analyses identified a group of genes with altered levels of expression. Some of these affected genes are associated with cell development and differentiation towards endodermal and epithelial tissues.

Epithelial tissue shows polarization. In many cases, neoplastic transformation is accompanied by the loss of the polarized phenotype typical of epithelial cells. Apical transport of protein takes place in epithelial tissue in two ways: direct and indirect pathways. Proteins transported indirectly are first directed to the basolateral surface. After proteins undergo endocytosis and are directed further to the apical surface by the transcryptotic pathway [20]. One of the proteins that play an important role in indirect protein transport is the MAL protein family, which has been detected in many normal epithelial cells isolating from the respiratory system, gastrointestinal tract, genitourinary tract and endocrine glands. Specific changes in MAL (T-cell differentiation protein) and MAL2 (T-cell differentiation protein 2) expression have been observed in certain types of cancer[21]. Lak et al. suggest that overexpression of MAL2 may promote the proliferation of breast cancer cells, while its knockout may 

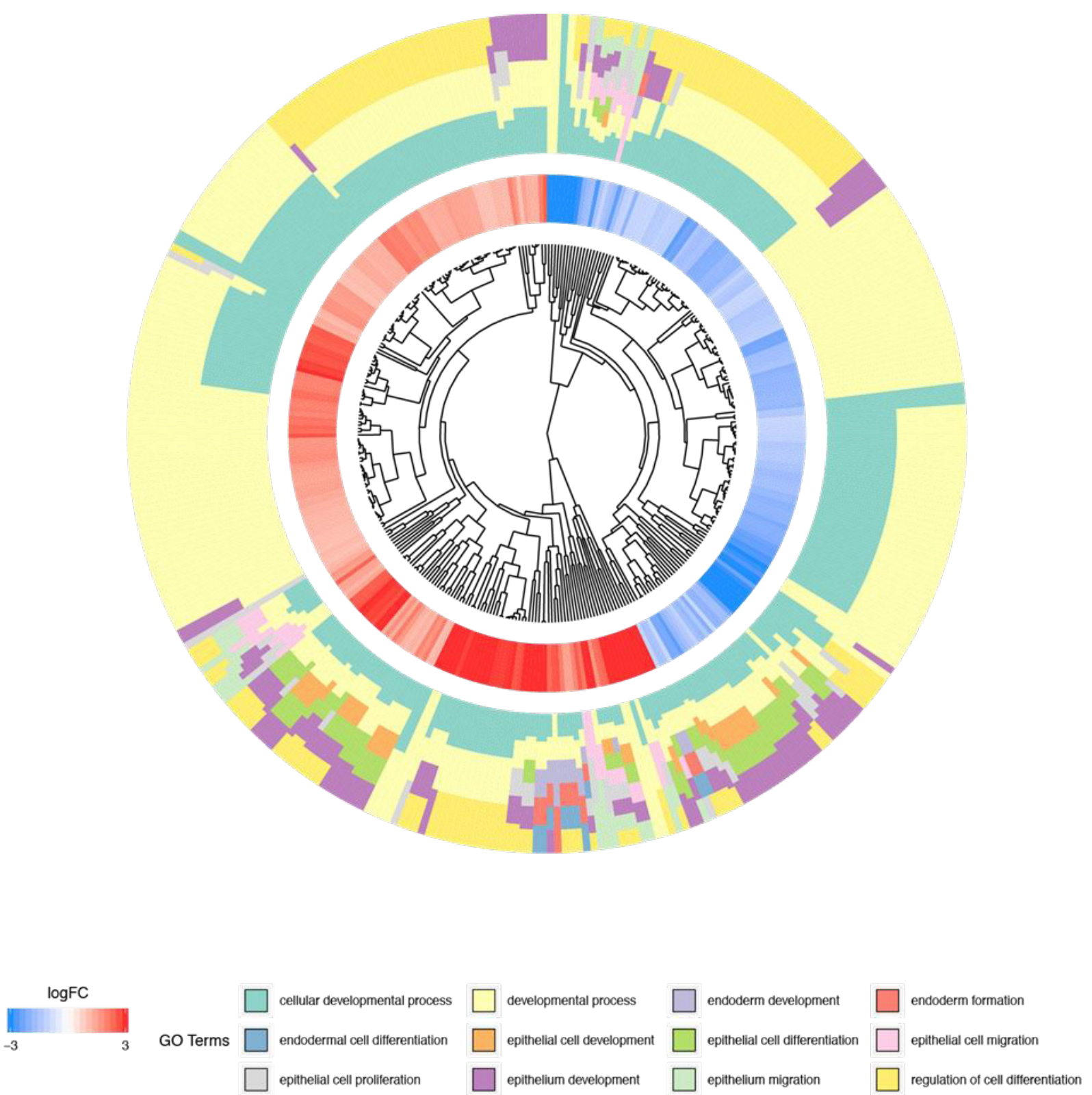

FIGURE 3. The dendrogram of differentially expressed genes involved in "developmental process", "cellular developmental process", "regulation of cell differentiation", "epithelium migration", “epithelial cell proliferation", "epithelial cell migration”, "epithelial cell differentiation", "epithelial cell development", "endodermal cell differentiation", "endoderm formation", "endoderm development" and "epithelium development" GO BP terms. The DEGs were clustered based on their logFC values

reduce the proliferation of breast cancer cancer cells [22]. A study by Zhou et al. suggest that tumor tissue cells and breast cancer cell lines showed decreased expression of ITM2A (integral membrane of 2A protein). On the other hand, overexpression of this gene significantly inhibited the proliferation of breast cancer cells, which qualifies ITM2A as a prognostic marker [23]. Moreover, the ITM2A gene, encoding a porcine protein that is highly homologous to the integrated 2A (ITM2A) membrane protein of humans and mice, was herby downregulated. The expression of this gene is observed in fat, spleen, lungs, muscles, liver, small intestine, large intestine and kidneys [24]. ITM2A was also observed to have a therapeutic potential for epithelial ovarian cancer, as it acts as a chemosensitizer and induces cell cycle arrest [25].

The experimental gene overexpression also had an inhibitory effect on the proliferation of breast cancer, DAB1 (DAB protein adaptor 1) [26].This gene encodes for an adaptive protein necessary for intracellular Reelin signal transmission, which, in turn, controls the migration and differentiation of postmitotic neurons in the brain development process [27]. Moreover, this gene plays important roles in cell morphogenesis, differentiation and devel- 


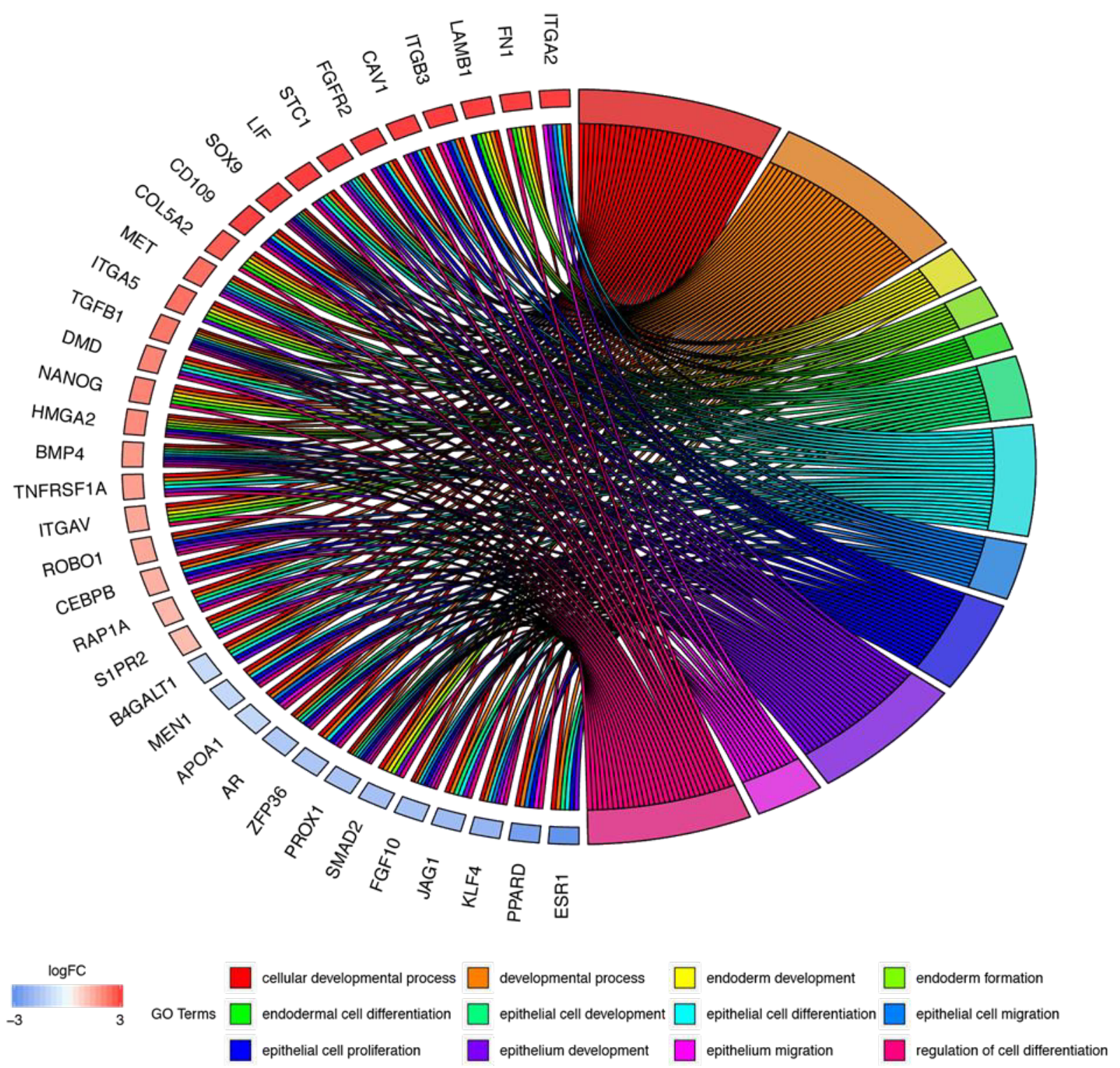

FIGURE 4. Analysis of enriched gene ontological groups involved in regulation of granulosa cells differentiation towards endodermal and epithelial tissues. The network plot presenting the linkages of genes and GO BP terms

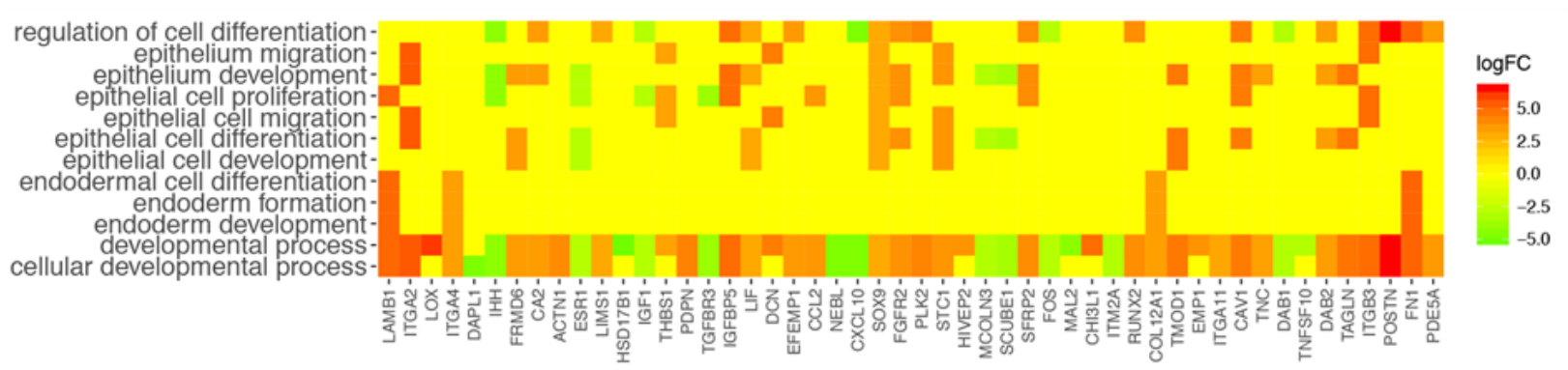

FIGURE 5. Heatmap presenting the relationship between genes and selected GO BP terms. The yellow color of tiles indicates the absence of $\log \mathrm{FC}$ values 


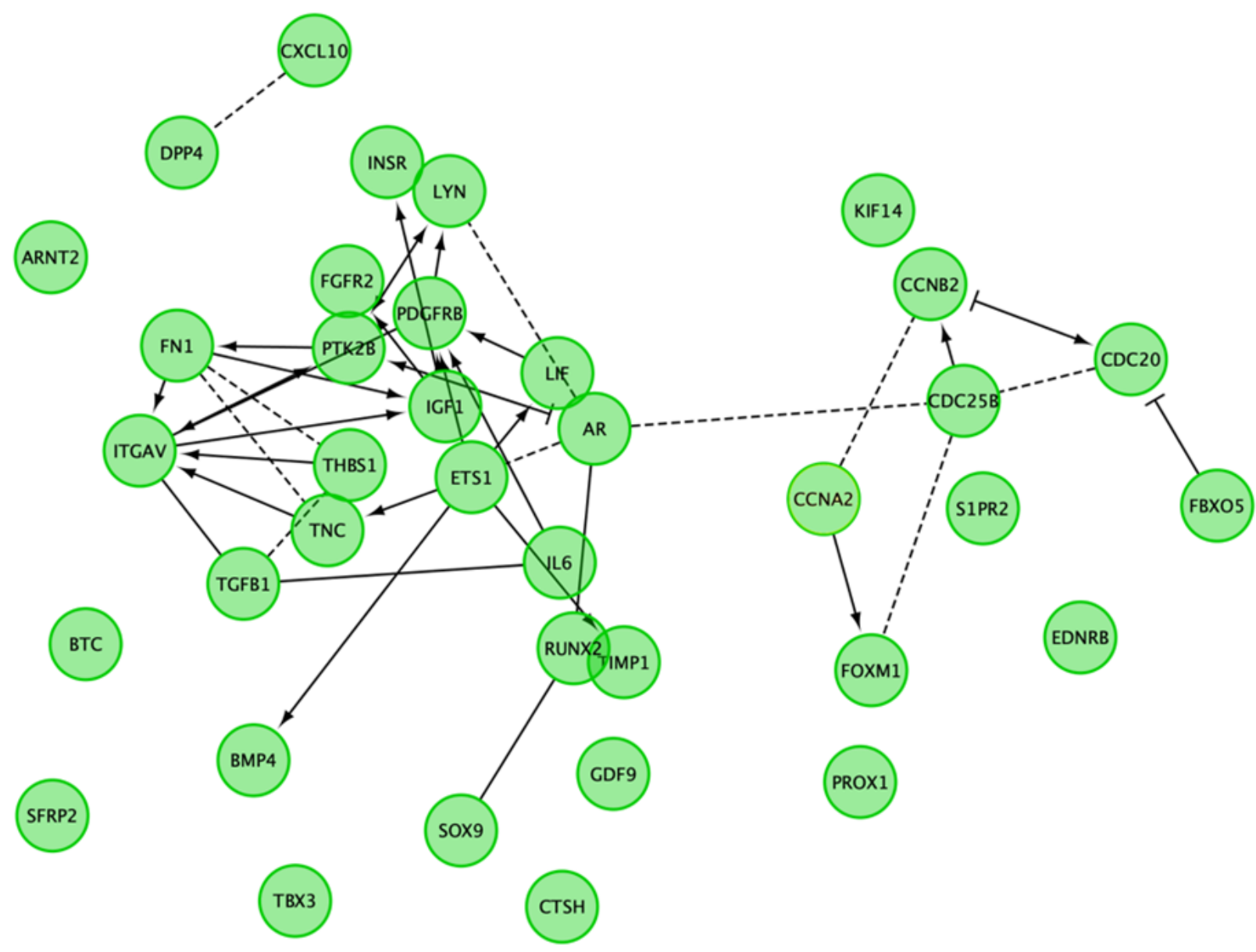

FIGURE 6. Reactome FI network for "positive regulation of cell proliferation". “---> indicates activating/catalyzing, "-|" for inhibition, "-" FIs extracted from complexes or inputs and "---" predicted FIs

opment, specifically in neuronal differentiation of granulosa cells [28].

Next downregulated gene is NEBL (nebulette). This gene encodes a nebulin-like protein that binds to actin and is highly expressed in the myocardium, playing an important role in Z-disk assembly [29]. It is abundant in the heart muscle, especially in the myocardium, where it assembles cardiac myofibril, combining sarcomeric actin with desmin fibers in sarcomeres [30,31].

Another gene showing downregulated expression in the presented studies is DAPL1 (death associated protein-like 1). This gene is involved in the early stages of epithelial differentiation, but also in the processes of apoptosis. Increased levels of expression of DAPL1 were observed in studies on uterine inflammation in dairy cows, analyzing levels of its transcripts in the endometrium [32]. It may show a different level of expression depending on the tissue [33]. Moreover, Chen et al. proved that DAPL1 is an important factor regulating steroidogenesis [34]. Zhang et al. noted that DAPL1 is less expressed in breast cancer cells than in other healthy tissues. Low expression of this gene was correlated with poor prognosis of survival in patients with breast cancer [35].

Finally, HSD17B1 was the most downregulated gene. Its product enzyme catalyzes the conversion of estrone to estradiol, and genetic variations of this gene are associated with the risk of breast and endometrial cancer, as well as modifying the susceptibility to endometriosis [36,37]. Its expression is observed in ovaries, placenta, testis, endometrium, malignant and normal breast epithelium, and prostatic cancer cells [38,39].

\section{Conclusions}

The changes in expression during long-term primary in vitro cultures of genes belonging to ontological groups associated with endodermal and epithelial tissues formation, differentiation and migration suggest that these genes response for endoderm and epithelial lineages formation. This study serves as a basic molecular reference for the potential further research on the protein level elucidating the functional meaning of several gene markers and on the mechanisms underlying GCs differentiation toward the lineages of interest. 


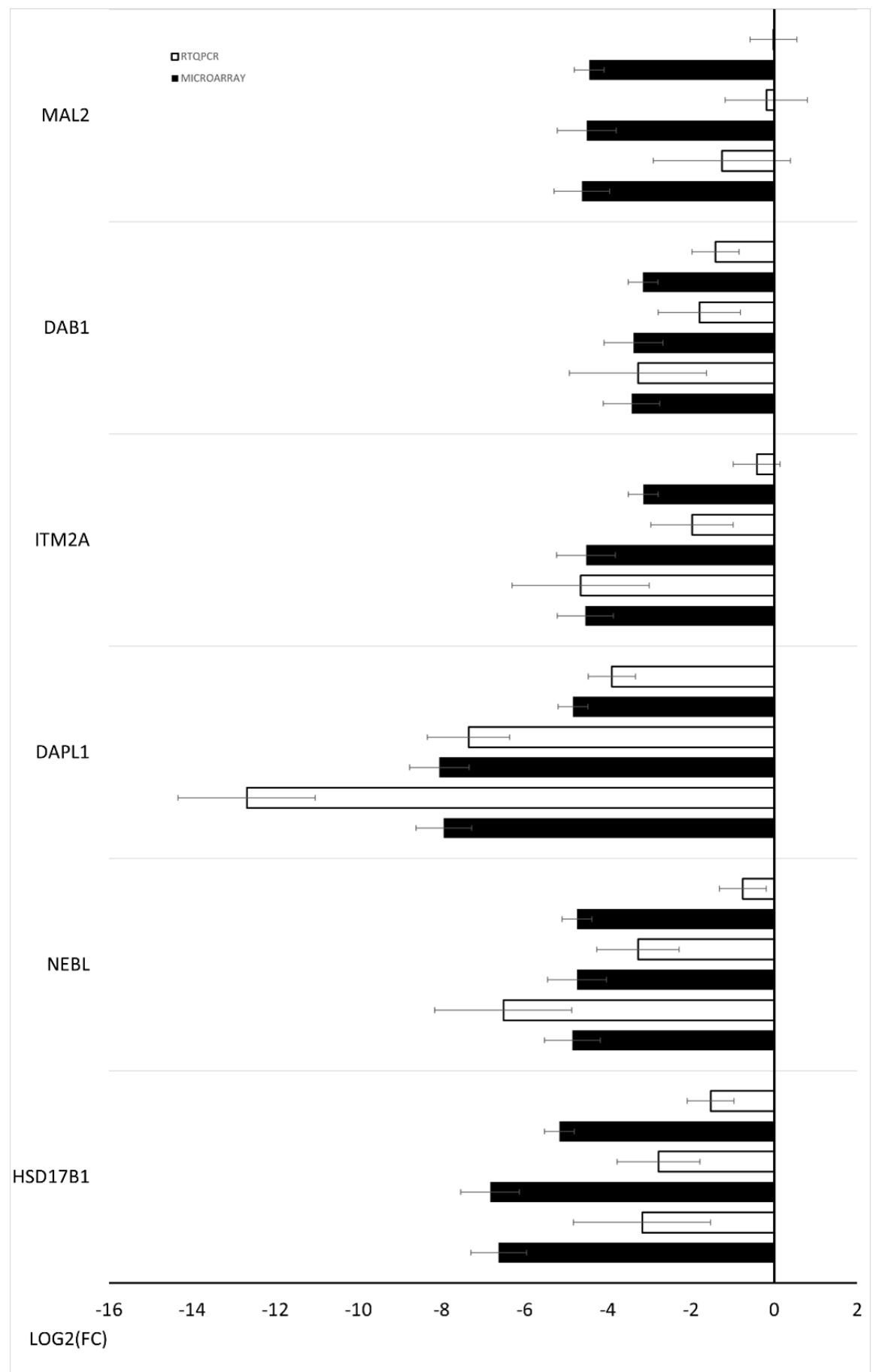

FIGURE 7. Microarray validation using RT-qPCR

\section{Ethical approval}

The ethical approval not required.

\section{Acknowledgments}

Not applicable.

\section{Corresponding author}

Paweł Antosik, Department of Veterinary Surgery, Institute of Veterinary Medicine, Nicolaus Copernicus University in Toruń, Gagarina 7 St., 87-100 Toruń, Poland, e-mail: pantosik@umk.pl.

\section{Conflict of interest}

The authors declare they have no conflict of interest.

\section{References}

1. Kossowska-Tomaszczuk K, De Geyter C, De Geyter M, Martin I, Holzgreve W, Scherberich A, Zhang H. The Multipotency of Luteinizing Granulosa Cells Collected from Mature Ovarian Follicles. Stem Cells. 2009;27(1):210-9; DOI:10.1634/stemcells.2008-0233.

2. Kranc W, Brązert M, Celichowski P, Bryja A, Nawrocki MJ, Ożegowska K, Jankowski M, Jeseta M, Pawelczyk L, Bręborowicz A, Rachoń D, Skowroński MT, Bruska M, Zabel M, Nowicki M, Kempisty B. 'Heart development and morphogenesis' is a novel pathway for human ovarian granulosa cell differentiation during long-term in vitro cultivation-a microarray approach. Mol Med Rep. 2019;19(3):1705-15; DOI:10.3892/mmr.2019.9837.

3. Brązert M, Kranc W, Celichowski P, Ożegowska K, Budna-Tukan J, Jeseta M, Pawelczyk L, Bruska M, Zabel M, Nowicki M, Kempisty B. Novel markers of human ovarian granulosa cell differentiation toward osteoblast 
lineage: A microarray approach. Mol Med Rep. 2019;20(5):4403-14; DOI:10.3892/mmr.2019.10709.

4. Kossowska-Tomaszczuk K, De Geyter C, De Geyter M, Martin I, Holzgreve W, Scherberich A, Zhang H. The Multipotency of Luteinizing Granulosa Cells Collected from Mature Ovarian Follicles. Stem Cells. 2009;27(1):210-9; DOI:10.1634/stemcells.2008-0233.

5. Dzafic E, Stimpfel M, Virant-Klun I. Plasticity of granulosa cells: On the crossroad of stemness and transdifferentiation potential. J Assist Reprod Genet. 2013;30(10):1255-61; DOI:10.1007/s10815-013-0068-0.

6. Rodgers RJ, Lavranos TC, Van Wezel IL, Irving-Rodgers HF. Development of the ovarian follicular epithelium. Mol Cell Endocrinol. 1999;151(12):171-9; DOI:10.1016/S0303-7207(99)00087-8.

7. Wells JM, Melton DA. Vertebrate Endoderm Development. Annu Rev Cell Dev Biol. 1999;15(1):393-410; DOI:10.1146/annurev.cellbio.15.1.393.

8. Chomczynski P, Sacchi N. Single-step method of RNA isolation by acid guanidinium thiocyanate-phenol-chloroform extraction. Anal Biochem. 1987;162(1):156-9; DOI:10.1016/0003-2697(87)90021-2.

9. Walter W, Sánchez-Cabo F, Ricote M. GOplot: an R package for visually combining expression data with functional analysis: Fig. 1. Bioinformatics. 2015;31(17):2912-4; DOI:10.1093/bioinformatics/btv300.

10. Yates AD, Achuthan P, Akanni W, Allen J, Allen J, Alvarez-Jarreta J, Amode MR, Armean IM, Azov AG, Bennett R, Bhai J, Billis K, Boddu S, Marugán JC, Cummins C, Davidson C, Dodiya K, Fatima R, Gall A, Giron CG, Gil L, Grego T, Haggerty L, Haskell E, Hourlier T, Izuogu OG, Janacek SH, Juettemann T, Kay M, Lavidas I, Le T, Lemos D, Martinez JG, Maurel T, McDowall M, McMahon A, Mohanan S, Moore B, Nuhn M, Oheh DN, Parker A, Parton A, Patricio M, Sakthivel MP, Abdul Salam AI, Schmitt BM, Schuilenburg H, Sheppard D, Sycheva M, Szuba M, Taylor K, Thormann A, Threadgold G, Vullo A, Walts B, Winterbottom A, Zadissa A, Chakiachvili M, Flint B Frankish A, Hunt SE, Iisley G, Kostadima M, Langridge N, Loveland JE Martin FJ, Morales J, Mudge JM, Muffato M, Perry E, Ruffier M, Trevanion SJ, Cunningham F, Howe KL, Zerbino DR, Flicek P. Ensembl 2020. Nucleic Acids Res. 2020;48(D1):D682-8; DOI:10.1093/nar/gkz966.

11. Kõressaar T, Lepamets M, Kaplinski L, Raime K, Andreson R, Remm M Primer3-masker: Integrating masking of template sequence with primer design software. Bioinformatics. 2018;34(11):1937-8; D0I:10.1093/ bioinformatics/bty036.

12. Rao X, Huang X, Zhou Z, Lin X. An improvement of the $2^{\wedge}$ (-delta delta CT) method for quantitative real-time polymerase chain reaction data analysis. Biostat Bioinforma Biomath. 2013;3(3):71-85.

13. Virant-Klun I, Zech N, Rožman P, Vogler A, Cvjetičanin B, Klemenc P, Maličev E, Meden-Vrtovec H. Putative stem cells with an embryonic character isolated from the ovarian surface epithelium of women with no naturally present follicles and oocytes. Differentiation. 2008;76(8):843-56 DOI:10.1111/j.1432-0436.2008.00268.x.

14. Virant-Klun I, Rožman P, Cvjeticanin B, Vrtacnik-Bokal E, Novakovic S, Rülicke T, Dovc P, Meden-Vrtovec H. Parthenogenetic Embryo-Like Structures in the Human Ovarian Surface Epithelium Cell Culture in Postmenopausal Women with No Naturally Present Follicles and Oocytes. Stem Cells Dev. 2009;18(1):137-50; DOI:10.1089/scd.2007.0238.

15. Parte S, Bhartiya D, Telang J, Daithankar V, Salvi V, Zaveri K, Hinduja I. Detection, Characterization, and Spontaneous Differentiation In Vitro of Very Small Embryonic-Like Putative Stem Cells in Adult Mammalian Ovary. Stem Cells Dev. 2011;20(8):1451-64; DOI:10.1089/ scd.2010.0461.

16. Kranc W, Budna J, Kahan R, Chachuła A, Bryja A, Ciesiółka S, Borys S, Antosik MP, Bukowska D, Brussow KP, Bruska M, Nowicki M, Zabel M, Kempisty B. Molecular basis of growth, proliferation, and differentiation of mammalian follicular granulosa cells. J Biol Regul Homeost Agents. n.d.;31(1):1-8.

17. Ciesiółka S, Budna J, Jopek K, Bryja A, Kranc W, Chachuła A, Borys S, Dyszkiewicz Konwińska M, Ziółkowska A, Antosik P, Bukowska D, Brüssow KP, Bruska M, Nowicki M, Zabel M, Kempisty B. Influence of Estradiol-17beta on Progesterone and Estrogen Receptor mRNA Expression in Porcine Follicular Granulosa Cells during Short-Term, In Vitro Real-Time Cell Proliferation. Biomed Res Int. 2016;2016:8431018; DOI:10.1155/2016/8431018.

18. Johnson J, Canning J, Kaneko T, Pru JK, Tilly JL. Germline stem cells and follicular renewal in the postnatal mammalian ovary. Nature. 2004;428(6979):145-50; DOI:10.1038/nature02316

19. Dzafic E, Stimpfel M, Virant-Klun I. Plasticity of granulosa cells: On the crossroad of stemness and transdifferentiation potential. J Assist Reprod Genet. 2013;30(10):1255-61; DOI:10.1007/s10815-013-0068-0.

20. Marazuela M, Acevedo A, García-López MA, Adrados M, De Marco MC, Alonso MA. Expression of MAL2, an Integral Protein Component of the Machinery for Basolateral-to-Apical Transcytosis, in Human Epithelia. J Histochem Cytochem. 2004;52(2):243-52; DOI:10.1177/002215540405200212.
21. Marazuela M, Acevedo A, Adrados M, García-López MA, Alonso MA. Expression of MAL, an integral protein component of the machinery for raft-mediated pical transport, in human epithelia. J Histochem Cytochem. 2003;51(5):665-73; DOI:10.1177/002215540305100512.

22. Bhandari A, Shen Y, Sindan N, Xia E, Gautam B, Lv S, Zhang X. MAL2 promotes proliferation, migration, and invasion through regulating epithelial-mesenchymal transition in breast cancer cell lines. Biochem Biophys Res Commun. 2018;504(2):434-9; DOI:10.1016/J.BBRC.2018.08.187.

23. Zhou C, Wang M, Yang J, Xiong H, Wang Y, Tang J. Integral membrane protein $2 \mathrm{~A}$ inhibits cell growth in human breast cancer via enhancing autophagy induction. Cell Commun Signal. 2019;17(1):1-14; D0I:10.1186/ S12964-019-0422-7/FIGURES/4.

24. Liu GY, Ge CR, Zhang X, Gao SZ. Isolation, sequence identification and tissue expression distribution of three novel porcine genes - RAB14, S35A3 and ITM2A. Mol Biol Rep. 2008;35(2):201-6; DOI:10.1007/ s11033-007-9071-9.

25. Nguyen TMH, Shin IW, Lee TJ, Park J, Kim JH, Park MS, Lee EJ. Loss of ITM2A, a novel tumor suppressor of ovarian cancer through G2/M cell cycle arrest, is a poor prognostic factor of epithelial ovarian cancer. Gynecol Oncol. 2016;140(3):545-53; DOI:10.1016/j.ygyno.2015.12.006.

26. McAvoy S, Zhu Y, Perez DS, James CD, Smith DI. Disabled-1 is a large common fragile site gene, inactivated in multiple cancers. Genes, Chromosom Cancer. 2008;47(2):165-74; DOI:10.1002/GCC.20519.

27. Long H, Bock HH, Lei T, Chai X, Yuan J, Herz J, Frotscher M, Yang Z. Identification of alternatively spliced Dab1 and Fyn isoforms in pig. BMC Neurosci. 2011;12; DOI:10.1186/1471-2202-12-17.

28. Kulus M, Sujka-Kordowska P, Konwerska A, Celichowski P, Kranc W, Kulus J, Piotrowska-Kempisty H, Antosik P, Bukowska D, Iżycki D, Bruska M, Zabel M, Nowicki M, Kempisty B. New molecular markers involved in regulation of ovarian granulosa cell morphogenesis, development and differentiation during short-term primary in vitro culture-transcriptomic and histochemical study based on ovaries and individual separated follicles. Int J Mol Sci. 2019;20(16); DOI:10.3390/ijms20163966.

29. Hernandez DA, Bennett CM, Dunina-Barkovskaya L, Wedig T, Capetanaki Y, Herrmann H, Conover GM. Nebulette is a powerful cytolinker organizing desmin and actin in mouse hearts. Mol Biol Cell. 2016;27(24):386982; DOI:10.1091/mbc.E16-04-0237.

30. Purevjav E, Varela J, Morgado M, Kearney DL, Li H, Taylor MD, Arimura T, Moncman CL, McKenna W, Murphy RT, Labeit S, Vatta M, Bowles NE, Kimura A, Boriek AM, Towbin JA. Nebulette mutations are associated with dilated cardiomyopathy and endocardial fibroelastosis. J Am Coll Cardiol. 2010;56(18):1493-502; DOI:10.1016/j.jacc.2010.05.045.

31. Jiang G, Herron TJ, Bernardo J Di, Walker KA, O’Shea KS, Kunisaki SM. Human Cardiomyocytes Prior to Birth by Integration-Free Reprogramming of Amniotic Fluid Cells. Stem Cells Transl Med. 2016;5(12):1595606; DOI:10.5966/SCTM.2016-0016.

32. Salilew-Wondim D, Ibrahim S, Gebremedhn S, Tesfaye D, Heppelmann M, Bollwein H, Pfarrer C, Tholen E, Neuhoff C, Schellander K, Hoelker M. Clinical and subclinical endometritis induced alterations in bovine endometrial transcriptome and miRNome profile. BMC Genomics. 2016;17(1):218; DOI:10.1186/s12864-016-2513-9.

33. Sun L, Ryan DG, Zhou M, Sun TT, Lavker RM. EEDA: A protein associated with an early stage of stratified epithelial differentiation. J Cell Physiol. 2006;206(1):103-11; DOI:10.1002/JCP.20433.

34. Chen H bin, Pineda Garcia JC, Arizono S, Takeda T, Li R shi, Hattori Y, Sano H, Miyauchi Y, Hirota Y, Tanaka Y, Ishii Y. DAPL1 is a novel regulator of testosterone production in Leydig cells of mouse testis. Sci Reports 2021 111. 2021;11(1):1-12; DOI:10.1038/s41598-021-97961-6.

35. Zhang H, Qu X, Han L. Identification of death-associated protein-like 1 (DAPL1) as a novel prognostic biomarker of breast cancer 2020; DOI:10.21203/RS.2.24569/V1.

36. Lamp M, Peters M, Reinmaa E, Haller-Kikkatalo K, Kaart T, Kadastik Ü, Karro H, Metspalu A, Salumets A. Polymorphisms in ESR1, ESR2 and HSD17B1 genes are associated with fertility status in endometriosis. Gynecol Endocrinol. 2011; DOI:10.3109/09513590.2010.495434.

37. Setiawan VW, Hankinson SE, Colditz GA, Hunter DJ, De Vivo I. HSD17B1 Gene Polymorphisms and Risk of Endometrial and Breast Cancer. 2004.

38. Mannermaa A, Peltoketo H, Winqvist R, Ponder BAJ, Kiviniemi H, Easton DF, Poutanen M, Isomaa V, Vihko R. Human familial and sporadic breast cancer: analysis of the coding regions of the $17 \beta$-hydroxysteroid dehydrogenase 2 gene (EDH17B2) using a single-strand conformation polymorphism assay. Hum Genet. 1994;93(3):319-24; DOI:10.1007/ BF00212030.

39. Normand T, Narod S, Labrie F, Simard J. Detection of polymorphisms in the estradiol $17 \beta$-hydroxysteroid dehydrogenase II gene at the EDH17B2 locus on 17q11-q21. Hum Mol Genet. 1993; DOI:10.1093/ hmg/2.4.479. 